\title{
Editorial
}

\section{The protozoan view of the human condition}

I am delighted to be able to report on our recent Annual Conference where the parasite protozoa gathered together for our regular binge. This year's venue was luxurious; we were hosted by an indulgent European executive who had acquired sleeping sickness and malaria on a visit to East Africa. We all gathered in Mombasa where we were able to indulge our appetites unaffected by whatever drugs could be thrown at us. The trypanosomes remain undetected and are looking forward to reaching the brain in due course.

We met up with our friends, the amoebae who had decided to move from the less appropriate environment of the gut to the luxuriant liver; Entamoeba histolytica climbed on board our host when he was in Bombay and we also have a small delegation of Trichomonas from a nocturnal visit our indulgent host made to a nightclub in Bangkok some months ago. They are having a fine time tickling his suppurating appendage, which he thinks is due to our bacterial friends. $\mathrm{He}$ is mystified why the antibiotics he acquired in India from a disreputable source are not helping him. Leishmania major is also developing into a small lesion but 'boring John' as we call him is getting really upset about the rumour that he is going to be made extinct by a new vaccine (pie in the sky!). Three delegations arrived by air, the trypanosomes flew in on the new jumbo run by Air Glossina; falciparum who is leading the malaria delegation arrived late as usual on $A$ gambiae and the Leishmania had a really difficult journey, as sandfly can barely get off the ground these days. We expect that we will have to move on from this particular venue shortly as our host is rapidly running out of resources. Certainly there should not be any problems for those of us flying, as there are daily flights by Glossina and $A$ gambiae flies every night.

The president this year, Trypanosoma rhodesiense, was giving an overview of our situation. The historians have really made him happy as it seems his particular lineage is amongst the oldest; rhodesiense is also pretty pleased that there is no sign of any vaccine and they are still trying to kill him with arsenic! I must admit we all thought that at last 'rational' biochemistry had found a drug to kill us when they came up with this ornithine decarboxylase inhibitor (DFMO: difluoromethyl ornithine), which inhibits polyamine metabolism in rapidly dividing tumour cells, and found it 'worked nicely' in mice with trypanosomes. ${ }^{2}$ Well luckily it doesn't work in rhodesiense, so the theory doesn't fit the reality. We aren't prepared to explain why it works on gambiense (at $\$ 400$ a time!). Anyway it matters little as the drug company has stopped producing it! Another victory for the tryps! As far as arsenic is concerned, no one is worried either because the drug company only manufactures it occasionally. Countries cannot afford to buy it and few donors are interested in purchasing it to give to the few people left who know how to use it! The gambiense are proliferating all over Central Africa, particularly in Zaire, and the humans are unable to do anything, not even diagnose them. ${ }^{3} T$ rhodesiense also has another option as they can always go game watching for a few weeks in the bushbuck or hartebeest in the Serengeti; nobody disturbs them there. Some of them did have problems recently moving around when some clever person decided to bring down Glossina using traps containing insecticides and some very attractive smells (cow's urine!) to lure the flies, but luckily this was directed at cattle trypanosomes. They are even pouring insecticide onto cows to kill tsetse and ticks these days. ${ }^{4}$ Trypanosomes have really got it made: they are always changing their coats and, despite the scientific recession, people are still trying to understand how they manage to evade the immune response. Every year millions of pounds or dollars are spent trying to understand how we work, but so far we have successfully evaded all attempts to restrain us. Thousands of mice are used every year to harvest us in the hope that the magic bullet will arrive; all they produce are $\mathrm{PhDs}$.

The tryps here in Mombasa had a message from their cousins in Brazil who could not come over as it was Carnival (they felt they were better employed providing the Rio hospitals with heart attack patients from over-indulgence rather than acute Chagas disease). The other problem for $T$ cruzi and his mates was that the bugs just cannot fly across the Atlantic as they cannot take off with a full payload. They are also seriously demoralised by this campaign of spraying houses; the entomologists have also started to use paints and canisters full of nasties to kill Triatoma so life is getting a little tougher in South America. The other problem is they are screening the blood in blood banks for T cruzi as well as HIV and hepatitis B and that is not helping us spread around. Chagas is suffering as transmission is curtailed significantly after over 10 years of spraying Triatoma in the Southern Cone of South America. ${ }^{5}$ The disease is now reducing in incidence in Brazil, Chile, Uruguay, Argentina and Paraguay due to spraying homes and we have been unable to infect the children. However, whilst the fate of cruzi in the Southern Cone is under threat there are plenty of reservoir hosts and non-domiciliary bugs which will keep them going. Control in Bolivia is going to be difficult and in Venezuela our cousins can always survive in Rhodnius in palm trees, the natural habitat. It is ironic really, Rhodnius have been studied as insects for so long that more is known about their physiology than any insect but it hasn't had any impact on control!

This year the malaria parasites, particularly falciparum and his gang, are really smug. They were getting a little upset as people were running around saying "We've got a vaccine. We've got a vaccine". In a ceremony in Geneva, somewhat prematurely, the exclusive worldwide rights of this vaccine were given to the World Health Organisation. The Director-General said "I welcome the extraordinary generosity of Dr Pattaroyo in offering the vaccine to the world". It seemed to work in Colombia and the Tanzanian results seemed vaguely promising, but the poor results in Gambia and Thailand have made them really pleased; it does not look like there is a Nobel prize in malaria vaccines for some years yet! ${ }^{6,7}$ Anyway, how can anyone consider delivering a vaccine to children under 18 months in Africa on three occasions and achieve even a reasonable coverage? More recent studies of a new vaccine in American prisoners look more promising. However, despite the new drugs which are coming on stream our track record of overcoming any antimalarial they can throw at us is pretty good. Lariam has also had a bad press recently which means we have fewer problems getting established. Nasty nightmares and making people crazy has really helped falciparum. No doubt this year we will be challenged by artemisinine and atovaquone plus proguanil (malarone) but the cost of the latter and the widespread abuse of the artemisinine should 
not cause us a serious problem in the long term. Most antimalarials are sold by the private sector anyway and nobody takes the right dose. The major problem the malaria boys are facing is the impact of bednets on the flight schedules. The bednet trials look pretty good but I doubt they will be sustained when people have to pay! ${ }^{8}$ Another problem which no one seems to take into account is that the Anopheles have yet to play the pyrethroid resistance card. (Laboratory studies have shown that, in areas where pyrethroids are used in agriculture, they are gradually developing resistance.)

The Leishmania delegation is always a bit small when we have an African venue; they only tend to appear in large numbers in South America where they seem to manage to hitch rides on board every conceivable mammal, opossums, armadillos, all kinds of rats, porcupines, etc, and suddenly pop up in really nasty lesions inside macrophages. Again, Leishmania seems to have survived despite the antimonials thrown at them. New drugs have been developed such as ambisome (containing amphotericin $\beta$ in liposomes) and amosidine but they are still too expensive for the rural poor, even if available. Also they are not in any real danger from vector control as sandfly habitats are difficult to spray, except perhaps in urban environments; they are impossible to find in South America and no one yet knows where sandfly larvae live! Our friends HIV have had a dramatic impact on Leishmania in Europe as their immunosuppressive activities have shown how widespread Leishmania actually are without causing overt infection in nonimmunosuppressed hosts. Leishmania actually infects much larger numbers of people in Southern Europe than we wanted to be known but with HIV coming along it is now clear we are widespread.

We are, however, full of admiration for the brave attempts in South Sudan to contain our virulent attacks of visceral leishmaniasis by using up the last supplies of pentostam to treat the large numbers of cases we have induced in the war-ravaged populations. Jill Seaman's remarkable attempts to contain us should not go unnoticed as she has had to cope with difficulties in diagnosing us and in deciding who to treat with only limited drug supplies. And all this in the middle of a war. ${ }^{9}$ This situation is not dissimilar from that in Angola, with epidemic sleeping sickness in probably several hundred thousand people who are difficult to reach because of mines! Meanwhile conflict, which now pervades Africa, promotes our survival and permits us indeed to flourish.

One group who are a bit worried about not getting away from the conference are the Trichomonas. They had a great time before the tryps and malaria arrived because they went out every night and met up with some really interesting gonorrhoea, spirochaetes, chlamydia and HIVs. The last thing our host is going to think about is a dose of Flagyl (metronidazole). However, we stopped that, as the poor host isn't going anywhere now with tryps and malaria here! However, Trichomonas have had all the action as we tryps rarely, if ever, get sex; malaria can only get it when they are flying and Leishmania are not even supposed to have it, although some French groups claim to have seen Leishma-

1 Simpson L, Maslov D. Evolution of parasitism in kinetoplastid protozoa. Parasitol Today 1995; 11: $30-2$

2 Pepin J, Milord F. The treatment of human African trypanosomiasis. Adv Parasitol 1994; 33: $1-47$.

Ekwanzala M, Pépin J, Khonde N, et al. In the heart of darkness: sleeping sickness in Zaire. Lancet 1996; 348: 1427-30.

4 Green C. Bait methods for tsetse control. Adv Parasitol 1994; 34: 229-91.

5 Schuminis GA, Zicker F, Moncayo A. Interruption of Chagas' disease transmission through vector elimination. Lancet 1996; 348: 1171 .

6 Alonso P, Smith T, Armstrong Schellenber JR, et al. Randomised trial of efficacy of Spf66 vaccine against Plasmodium falciparum in children in Southern Tanzania. Lancet 1994; 344: 1175-81. nia at it. I don't reckon they have sex anyway - who would contemplate it in a sandfly, or even worse in a macrophage. Anyway we flagellates, despite our name, have been pretty discrete about sexual activities and we intend to continue to be.

The amoeba don't need to worry at present; nobody is gunning for them unless our host takes the Flagyl. They spend most of their time lazing around in the gut engulfing red cells and then going to sleep as boring cysts. What a life!

At the end of the speech rhodesiense gave us the benefits of a SWOT analysis on the protozoan parasites of humans.

\section{Strengths}

- no available vaccines or likely to be limited, toxic drugs only available for Leishmania and Trypanosoma

- effective prolonged treatment is usually not available or affordable

- although drugs are available for malaria, resistance is rapidly developed

- we are often transmitted by abundant and highly adaptable vectors which are not controlled (except bugs)

- mosquitoes can develop insecticide resistance and sandfly larvae are impossible to find

- reservoir hosts of trypanosomes and leishmania provide perfect refuges

- diagnosis is difficult; the most sensitive diagnostic methods are expensive and rarely deployed widely

- the lack of interest in investing in new drug development or a lack of resources to do anything about us

\section{Weaknesses}

- insecticides, if appropriately used, might impact on our vectors

\section{Opportunities}

- development projects and changing environments for vectors promote dispersion of new hosts and habitats

- more rapid development of drug resistance as a result of drug abuse

- interest in global climate change has effectively diverted the enemy's attention from our immediate activities

\section{Threats}

- vaccine development in Leishmania

- possible finding of 'magic bullet' drugs for Leishmania and trypanosomes

- intensive deployment of vector control by health systems - more efficient microbial-based insecticides.

After an excellent conference dinner we got on board our vectors just as our host succumbed, with the knowledge that the Society was in excellent shape and could look forward to a future of growth and progress.

\section{DH MOLYNEUX \\ Liverpool School of Tropical Medicine, Liverpool L3 $5 Q A, U K$}

Accepted 23 July 1997

7 D'Alessandro U, Leach A, Drakeley CJ, et al. Efficacy trial of malaria vaccine Spf66 in Gambian infants. Lancet 1995; 346: 462-7.

8 Nevill CG, Some ES Mung'ala VO, et al. Insecticide-treated bednets reduce mortality and severe morbidity from malaria among children on the Kenyan coast. Trop Med Int Health 1996; 1: 139-46.

9 Seaman J, Ashford RW, Schorscher J, et al. Visceral leishmaniasis in southern Sudan: status of healthy villagers in epidemic conditions. Ann Trop Med Parasitol 1992; 86: $481-6$. 